\title{
Improving Salt Tolerance of Lowland Rice Cultivar 'Rassi' through Marker-Aided Backcross Breeding in West Africa
}

Isaac Kofi Bimpong ${ }^{1}$ k.bimpong@cgiar.org; Tel. + 22133962 6445; Fax: + 221339626491 (corresponding author)

Baboucarr Manneh ${ }^{1}$ b.manneh@cgiar.org

Mamadou Sock ${ }^{1}$ m.sock@cgiar.org

Faty Diaw ${ }^{1}$ f.Diaw@cgiar.org

Nana Kofi Abaka Amoah ${ }^{1}$ n.amoah@cgiar.org

Abdelbagi M Ismail'² a.ismail@irri.org

Glenn Gregorio 2 g.gregorio@irri.org

Rakesh Kumar Singh ${ }^{2}$ r.k.singh@irri.org

Marco Wopereis ${ }^{3}$ m.wopereis@cgiar.org

${ }^{1}$ Africa Rice Centre, Sahel Regional Station, B.P 96, Saint Louis, Senegal

${ }^{2}$ International Rice Research Institute (IRRI), DAPO Box 7777, Metro Manila, Philippines

${ }^{3}$ Africa Rice Centre, 01 BP 2031, Cotonou, Benin

The authors wish it to be known that, in their opinion, the first 2 authors should be regarded as joint first authors.

\begin{abstract}
Salt stress affects about $25 \%$ of the 4.4 million ha of irrigated and lowland systems for rice cultivation in West Africa (WA). A major quantitative trait locus (QTLs) on chromosome 1 (Saltol) that enhances tolerance to salt stress at the vegetative stage has enabled the use of marker-assisted selection (MAS) to develop salt-tolerant rice cultivar(s) in WA. We used 3 cycles
\end{abstract}


of backcrossing with selection based on DNA markers and field-testing using 'FL478' as tolerant donor and the widely grown 'Rassi' as recurrent parent. In the $\mathrm{BC}_{3} \mathrm{~F}_{2}$ stage, salt-tolerant lines with over $80 \%$ Rassi alleles except in the region around Saltol segment were selected. 429 introgression lines (Saltol-ILs) were identified as tolerant at vegetative stage, of which 116 were field-tested for four seasons at the reproductive stage. Sixteen Saltol-ILs had less yield loss (3$26 \%$ relative to control trials), and 8 Saltol-ILs showed high yield potential under stress and nonstress conditions. The 16 Saltol-ILs had been included for further African-wide testing prior to release in 6 WA countries. MAS reduced the time for germplasm improvement from at least 7 to about 4 years. Our objective is to combine different genes/ QTLs conferring tolerance to stresses under one genetic background using MAS.

Keywords: High grain yield, Introgression lines, Lowland rice, Marker-aided Backcross breeding (MABC), Salt stress, Saltol QTL 


\section{Introduction}

Salt stress -both salinity and sodicity- is the second most widespread soil problem after drought and is a serious constraint in rice production worldwide. In excess of $25 \%$ of the 4.4 million ha of irrigated, lowland environments, mangrove swamp and deep-water systems for rice cultivation in West Africa are directly affected by salt stress [1]. A soil is considered saline if the electrical conductivity of its saturated extract $(E C e)$ is above $4 \mathrm{dS} \mathrm{m}^{-1}[2]$. A recent survey in 18 sub-Saharan Africa (SSA) countries noted that more than $30 \%$ of rice farmers consider salt stress as a major constraint due to grain yield loss up to $36 \%$ [3].

Rice is more sensitive to salt stress at seedling and reproductive stages. Salt tolerance at these two stages is, however, weakly associated [4]. Discovering and combining suitable tolerance traits for both stages is essential for developing better salt tolerant cultivars. The level of salt tolerant cultivars depends on environmental conditions. The effect of salt stress is often more severe in arid climates than in humid conditions. For example, grain yield loss of $50 \%$ at an ECe of $9.5 \mathrm{dS} \mathrm{m}^{-1}$ have been noticed in the humid tropics, while in the dry seasons at the arid Sahelian, an equivalent grain yield loss was observed at an ECe of only $3.5 \mathrm{dS} \mathrm{m}^{-1}$ [5].

The grain yield loss under salt stress conditions can be minimized using better crop and water managements through efficient irrigation schemes, better infrastructure and hydrological controls in addition to optimal use of fertilizer. The costs of adopting these measures are, however, very high for most of the resource-poor African farmers and also for the local governments. The grain yield gap in salt-prone soils can be decreased using a plant breeding 
approach, as its contribution to food security and poverty alleviation has been well documented [6].

It has been a big challenge for rice breeders to develop high yielding salt-tolerant cultivars in the lowlands. There is, therefore, an urgent need to breed rice cultivars that can adapt to salt stress. The sequencing of rice genome [7] has made available a great number of precisely located molecular markers, including SSRs and has permitted the positioning along chromosomes of reliable QTLs for many abiotic and biotic stresses. Marker-assisted selection (MAS) is a tool that can efficiently boosts the versatility of plant breeders in selecting desirable crop traits. Its main advantages are its efficiency in precise selection; shortening the breeding cycle, and its ability to handle a large segregating population [8]. Due to its robustness, MAS has been adopted by numerous researchers working towards improving rice for several biotic and abiotic stresses. Some successful stories from MAS in rice breeding include the incorporation of bacterial blight resistance gene $X a 21$, waxy gene and submergence tolerance sub1a gene into elite cultivars $[9,10]$.

A single major QTL designated as Saltol and mapped on chromosome 1 confers salt tolerance at the vegetative stage and explains about $64 \%$ to $80 \%$ of the phenotypic variance in salt uptake [11]. This QTL is fine-mapped and various DNA markers closely linked to it have been developed and are being used to transfer the QTL into cultivars widely grown in many Asian countries where salt stress is a major constraint. The abundance of salt-sensitive cultivars widely grown by farmers in SSA provides an opportunity to breed cultivars that would be suitable for larger areas in the lowlands. Saltol introgression lines (Saltol-ILs) such as BR11-SalTol and BRRI dhan28-SalTol have been field-tested in salt-affected coastal regions of the Philippines, 
Bangladesh, India, and also in Vietnam, MAS improved salt tolerance in the 'OMCS2000' rice cultivar, which is widely grown [12].

The objectives of this research were (i) to introgress a QTL for early seedling salt-tolerance, Saltol, into the lowland cultivar, Rassi, widely grown in The Gambia and Senegal, through a targeted MAS approach; (ii) to evaluate the response of different Saltol -ILs produced for salt stress at both the seedling and reproductive stages, (iii) to identify high yielding Saltol -ILs showing adaptation to salt stress, which could be further used for diversifying sources for this trait by rice breeding programs, and (iv) to disseminate and validate promising ILs among saltprone lowlands in West Africa.

\section{Materials and Methods}

\subsection{Plant materials and crossing scheme}

Hybridizations were made between 2009 and 2011 in the screenhouse of the AfricaRice Sahel Regional Station near Saint Louis in Senegal, West Africa. 'FL478' (IR66946-3R-178-1-1), which is a tolerant indica recombinant inbred line, derived from 'IR29' and 'POKALLI B' [13], was used as the donor of Saltol. In this study, 'Rassi', derived from a cross between 'TN1' and 'Co29' and introduced from India, was selected as the recipient parent because it is widely grown in the Gambia and Senegal.

'Rassi' was crossed with FL478 to obtain $F_{1}$ seeds (Fig. 1). $F_{1} s$ were backcrossed with 'Rassi' to obtain $219 \mathrm{BC}_{1} \mathrm{~F}_{1}$ seeds. In the $\mathrm{BC}_{1} \mathrm{~F}_{1}$ generation, individual plants that were heterozygous at the Saltol locus were identified thereby reducing the population size for further screening (foreground selection). From the individual plants that were heterozygous for Saltol, those that were homozygous for the recipient allele at one marker locus (RM10655 for upper and RM493 
for lower) flanking the Saltol locus (i.e. recombinant) were identified; and referred to as "recombinant selection" [14]. Only 24 out of 151 polymorphic SSR markers were used for background selection. Individuals with the fewest were selected (background selection). In the $2^{\text {nd }}$ and $3^{\text {rd }}$ backcross generations $\left(\mathrm{BC}_{2}\right.$ and $\left.\mathrm{BC}_{3}\right)$ the same strategy was followed for selection of individual plants with the desired allele combination at the target loci including selection for recombinants between Saltol and the nearest proximal markers and suitable genomic composition at the non-target loci. Selected $\mathrm{BC}_{3}$ plants were self-pollinated for further analysis.

\subsection{Molecular marker analysis}

DNA was extracted from 21-day old seedlings from the screenhouse using the protocol of Dellaporta et al. [15] with some modifications. DNA was dissolved in $200 \mu \mathrm{l}$ of $1 \mathrm{X}$ TE buffer and stored at $-20^{\circ} \mathrm{C}$. A working stock was prepared by diluting the extracted DNA to $25 \mathrm{ng} / \mu \mathrm{l} \mathrm{using}$ double-distilled water. Markers were described in previous studies $[12,16,17]$. They are listed in supplementary table 1. Polymerase chain reaction (PCR) amplification and detection for SSR and gene specific markers was performed on a G-storm system (96 and 384-well alpha unit). The protocol for PCR amplification and detection of markers is basically the same as described in Chin et al. [18]. We used an 8\% non-denaturing polyacrylamide gel electrophoresis (PAGE) to obtain a high resolution following a modified procedure by AfricaRice Biotechnology Laboratory at Senegal [16]. The whole vertical rig assembly was then set in place with 1XTBE as running buffer. Four microliters of PCR product mixed with another $4 \mu \mathrm{L}$ of $6 \times$ loading dye were loaded into the wells with $50 \mathrm{bp}$ ladder. Voltage was set at $100 \mathrm{v}$ and running time for electrophoresis was variable ranging from 1.5 to $3.5 \mathrm{~h}$ depending on the expected size of the PCR product for the marker. The gels were stained with ethidium bromide for 10 to 15 minutes. DNA bands 
were visualized under UV light using gel documentation systems. Gel scoring was done manually.

\subsection{Foreground and recombinant selection}

At the initial stages of the experiment, for selection of the Saltol locus (foreground), the reported 30 markers comprising of 26 rice SSR markers and 4 gene-specific markers that cover the Saltol locus at a distance between $10.8 \mathrm{Mb}$ and $15.8 \mathrm{Mb}$ on chromosome 1 [16, 17] were used to identify polymorphism between the donor and the recipient parents. Two markers (AP3206F and RM10748) tightly linked to Saltol were selected and used in the foreground selection (Supplementary table 1). The donor allele for the Saltol locus is most similar to that of Pokkali accession IRGC 28609.

Selection of individual plants homozygous for the recipient allele at one marker locus was done using RM10655 and RM493 for upper (10.4 Mb) and lower (12.2Mb) flanking regions of the Saltol locus respectively (Supplementary table 1 ). Individual $\mathrm{BC}_{n} \mathrm{~F}_{1}$ plants were first selected based on the heterozygous nature of all the target loci at Saltol region. Only a few of such selected individuals that had the least donor alleles of the background markers were chosen to be backcrossed with 'Rassi' (Fig. 1)

\subsection{Background selection}

SSR markers unlinked to Saltol covering the 12 chromosomes and polymorphic between the two parents, were used for background selection to recover the recipient allele genome. Based on the polymorphism information, evenly spaced SSR markers were selected per chromosome. At least 24 polymorphic SSR markers covering the 12 chromosomes were used for initial background selection on $\mathrm{BC}_{1} \mathrm{~F}_{1}$ and 20 for $\mathrm{BC}_{2} \mathrm{~F}_{1}$ and $\mathrm{BC}_{3} \mathrm{~F}_{1}$ (Supplementary table 2). Four 
markers that revealed fixed (homozygous) alleles at non-target loci during the $\mathrm{BC}_{1} \mathrm{~F}_{1}$ generation were discarded. A total of 302 markers covering the 12 chromosomes were used for the parental polymorphism screening. There were 151 polymorphic markers that were further used for assessment on $\mathrm{BC}_{3} \mathrm{~F}_{3}$ generations as background selection (Supplementary fig. 1 and Supplementary table 2).

\subsection{Screening for Salt Stress Tolerance}

The MAS produced lines were screened for salt stress at the seedling stage using salinized nutrient solution in screenhouse and the most tolerant lines were then evaluated in field trials under salt stress and non-salt conditions during the subsequent wet and dry seasons

\subsubsection{Screenhouse trial}

In the screen house trial, the IRRI protocol for rapid screening for salt tolerance at the vegetative stage using salinized Yoshida solution was followed [19]. Altogether, $2380 \mathrm{BC}_{3} \mathrm{~F}_{2}$ along with parents and susceptible check 'IR29' were germinated in petri dishes. Five-day old seedlings were transferred to Styrofoam floats placed on plastic basins containing distilled water. Three days later, the distilled water was replaced with salinized Yoshida's solution, with slight modifications as per the protocol by Singh and Flower [20]. Salt stress was initially maintained at ECe $6 \mathrm{dSm}^{-1}$ by adding $\mathrm{NaCl}$ solution and was increased to $12 \mathrm{dSm}^{-1}$, three days later. This concentration was maintained for the rest of the trial. The $\mathrm{pH}$ of the nutrient solution was maintained at approximately 5.0 and the solution renewed weekly throughout the experiment.

Seedling vigor was scored 10 and 16 days after initial salinization based on response to salt stress using the standard evaluation score SES [21]. At the end of the experiment, surviving 
plants were transferred into pots with lowland soil for seed production. Screenhouse temperature recorded during the experiments ranged from 17 and $28^{\circ} \mathrm{C}$ in the morning and 36 to $44{ }^{\circ} \mathrm{C}$ in the afternoon. The mean relative humidity varied between $35 \%$ and $95 \%$.

\subsubsection{Experimental site for field screening}

Field screening was conducted at AfricaRice research farms in Ndiaye, Senegal $\left(16^{\circ} 32.141 \mathrm{~N}\right.$; $\left.15^{\circ} 11.545 \mathrm{~W}\right)$ for the non- salt trial and at Institut Senegalais de Recherché Agricoles (ISRA) research field in Ndiol, Senegal for the salt-stress environment. Both sites are located in the Senegal river valley and close to the coast (about $40 \mathrm{~km}$ inland). The soil at the site is a typical Orthithionic gleysol and contains at least $10 \mathrm{mg} \mathrm{C} \mathrm{kg}^{-1}$ of soil and $5 \mathrm{mg} \mathrm{P} \mathrm{kg}^{-1}$ (P-Bray1). The climate at both sites is characterized by a wet season with approximately $200 \mathrm{~mm}$ rainfall per year from July to October, a cold dry season from November to February, and a hot dry season from March to June. Trials in lowlands under irrigated conditions where no salt stress was imposed are referred to as non-stress trials.

\subsubsection{Field Screening of $B C_{3} F_{3}$ Saltol-ILs in 2011-2012 WS}

During the 2011-2012 wet seasons, $500 \mathrm{BC}_{3} \mathrm{~F}_{3}$ ILs from the validated Saltol-ILS with an SES score of 1 , selected from the screen house trial, were screened in the naturally saline at Ndiol, Senegal fields with the two parents to reduce the number of Saltol-ILs for subsequent field testing. Transplanting was done 25 days after sowing using one seedling per hill at a spacing of $20 \times 20 \mathrm{~cm}$. Each progeny row was flanked by single rows of the two parents. After transplanting, approximately $5 \mathrm{~cm}$ of standing water was maintained in the field until initiation of salt stress. After measuring the salt level, salinization was done by broadcasting measured 
quantities of granular $\mathrm{NaCl}$ in order to attain the desired salt level of $6 \mathrm{dSm}^{-1}$. Salt levels were continuously monitored in the trial by sampling soils 3 times a week from maximum tillering until maturity and adjusted accordingly. Weed control was done using a post-emergence herbicide and by hand weeding. Inorganic fertilizer was applied at $150-60-60 \mathrm{~kg} \mathrm{ha}^{-1} \mathrm{NPK}$, in both non-stress and stress trials. $40 \%$ of the nitrogen was applied both as basal treatments and at maximum tillering, and the remaining $20 \%$ at panicle initiation. $\mathrm{P}$ and $\mathrm{K}$ were applied as basal fertilizer.

\subsubsection{Field screening of $B C_{3} F_{4}$ Saltol-ILs in 2011-2012 DS}

From the 2011-2012 WS saline field trials, 116 Saltol-ILs with SES score of 3 were selected and advanced to $\mathrm{BC}_{3} \mathrm{~F}_{4}$. These selected lines were characterized agro-morphologically in non-salt field trials at Ndiaye and evaluated again for salt stress at Ndiol, Senegal during the 2012-2013 DS. Three replications were used in the saline field trial and 2 replications in the non-saline trial. 28 day old seedlings were transplanted in $2 \mathrm{~m}$ long rows per line at spacing of $20 \mathrm{~cm} \times 20 \mathrm{~cm}$ within and between rows. The same cultural practices were followed as described in sub section 2.5.3. The experiment was laid out in a $3 \times 4$ alpha-lattice design with 12 hills per plot.

\subsubsection{Selection of promising Saltol -ILs and population advancement}

Evaluation of each generation followed the same procedure as described in sub sections 2.5.3 and 2.5.4. All selected lines were screened under salt and non-salt conditions. Individual IL showing tolerance based on salt stress score, grain yield and components from $\mathrm{BC}_{3} \mathrm{~F}_{3}$ field experiment were selected and their derived $\mathrm{BC}_{3} \mathrm{~F}_{4}$ evaluated in the following season. The selection process was continued for two more seasons (2012-2013 and 2013-2014 wet season) until the $\mathrm{BC}_{3} \mathrm{~F}_{6}$ using the same procedure and data collection described in sub section 2.5.4, 
except that we used $80 \mathrm{BC}_{3} \mathrm{~F}_{6}$ ILs to conduct the experiments. This was done after background selection with 151 polymorphic DNA markers to select ILs with minimal donor alleles at nontarget loci (Supplementary fig. 1 and supplementary table 2).

\section{Growth and yield analysis.}

Data was recorded on yield, yield components and agronomic traits, including days to $50 \%$ heading (number of days from sowing till when $50 \%$ of plant stands are flowering); plant height (measured in $\mathrm{cm}$ from the soil surface to the tip of the tallest panicle-awns excluded); tiller number (counted as number of tillers per hill); score of salt injury (recorded in the salinized condition 83 and 100 days after transplanting using IRRI's standard evaluation (SES) system: 1 for tolerant, 3 for moderately tolerant and above 5 for sensitive); panicle sterility (estimated as total number of unfilled grains in a panicle from the total number of filled grains on the panicles and expressed as percentage); 1,000-seed weight (measured as weight in grams of 1,000 fully filled seeds per plant); number of panicles $\mathrm{m}^{-2}$ (estimated as number of panicles per $\mathrm{m}^{2}$ ); number of seeds per panicle (estimated as number of fully filled seed per panicle). Grain yield and moisture content were also recorded and the economic yield was adjusted to $14 \%$ moisture content. Grain moisture content was measured with a handheld grain moisture meter (Kett Riceter J-301, Japan). Grain yield was determined on a $0.4 \mathrm{~m}^{2}$ area in the middle of each plot after removing the borders and calculated as a product of the weight of fully filled seed, number of panicles $\mathrm{m}^{-2}$ and number of seed per panicle.

\subsection{Statistical Analysis}


Statistical analysis was performed using SAS v9.2 [22]. Mixed models were employed in which ILs were treated as fixed effects, whereas replicates and blocks within replicates (wherever applicable) were regarded as random effects. Least squares estimates of each trait on each ILs were obtained using the GLM option of the SAS MIXED procedure.

\section{Results and Discussion}

\subsection{MAS used to transfer salt tolerance QTL (Saltol) into popular African cultivar}

Our study focuses on combining the useful agronomic traits of Rassi with Saltol QTL, which enhances salt tolerance in backcross breeding lines by conversion to the recurrent parent genotype using molecular genotyping with SSR markers.

\subsubsection{Foreground and Recombinant Selection}

Two polymorphic markers (AP3206F and RM10748) tightly linked to Saltol were selected from a total of 30 markers covering the Saltol locus. They are at $10.8 \mathrm{Mb}$ to $15.8 \mathrm{Mb}[11,16]$ from the Saltol locus and were used in the foreground selection (Supplementary table 1). The 2 flanking markers used in our study were within the range of the Saltol loci (11.2 Mb-11.7Mb). The use of two precise markers resulted in minimizing the introgression size of the Saltol in the WA cultivar and also reduced the crossing over between the QTL regions, thus resulting in the decrease of false-positives arising from foreground selection. Of the $219 \mathrm{BC}_{1} \mathrm{~F}_{1}$ plants, $64(29 \%)$ were heterozygous for the two markers linked to Saltol. This percentage was appropriate as $75 \%$ of the $\mathrm{BC}_{1} \mathrm{~F}_{1}$ plants are expected to show the recurrent parent alleles and only about $25 \%$ should show those of the donor parent. They were therefore selected for recombinant selection with flanking markers. Flanking markers for recombinant selection should be chosen 
as closely linked as possible to the introgressed gene or QTL to minimize linkage drag [23]. The target of recombinant selection in $\mathrm{BC}_{1} \mathrm{~F}_{1}$ generation was to obtain single recombinants at one side of the Saltol QTL. In this study, selection of individual plants homozygous for the recipient allele at one marker locus was done by using RM10655 marker for upper flanking and RM493 for lower flanking region of the Saltol locus. Together with background selection (see below) 13 recombinants were obtained (Table 1), which minimized the size of the introgression of the Saltol locus. The intensity of selection for these 13 recombinants from $64 \mathrm{BC}_{1} \mathrm{~F}_{1}$ was comparatively lower vis-à-vis other rice breeding research done elsewhere. For instance Seraj et al. (24) in conducting similar studies for salt tolerance, selected 28 progenies out of 135 from $\mathrm{BC}_{1} \mathrm{~F}_{3}$ population between 'BR11' $\times$ ' $\mathrm{FL} 478$ ', and in other population at $\mathrm{BC}_{2} \mathrm{~F}_{3}$, they selected 138 out of 148. In the introgression of submergence tolerance gene Sub1, $20 \mathrm{BC}_{1} \mathrm{~F}_{1}$ were selected from 376 progenies and 11 out of $18 \mathrm{BC}_{3} \mathrm{~F}_{1}$ progenies after recombinant selection from the 2 populations [10].

\subsubsection{Background selection}

Background selection accelerates recovery of the recurrent parent genome [25]. Research on the effect of marker density on the recovery of recurrent parent genome have shown that a marker density of 2 or 3 markers per $100 \mathrm{cM}$ distance with a population size of 30 to 250 is optimal for controlling the genetic background of the recurrent parent genome at early backcross generations $\left(\mathrm{BC}_{1}-\mathrm{BC}_{3}\right)[23 ; 25]$.

We used 24 markers covering the 12 chromosomes (with 2 markers located apart on each chromosome) in the $\mathrm{BC}_{1} \mathrm{~F}_{1}$ stage as the background selection (Supplementary table 2). This enabled us to successfully identify 13 introgression lines with recurrent allele ranging between 
62.5 to $87.5 \%$. The use of 2 markers per chromosome for background selection was appropriate because two to three markers per $100 \mathrm{cM}$ are optimal for controlling the genetic background of the recurrent parent (25). Visscher et al. [26] proposed the use of two markers at a distance of $28 \mathrm{cM}$ from the telomeres, while Servin and Hospital [27] proposed to place two markers at 20 $\mathrm{cM}$ from the telomeres.

Various $(10,12,23,32$ and 56) number of markers have been used for background selection at different stages of MAS $[10,28]$. The best 5 plants (P45, P61, P73, P78 and P101) with recurrent allele composition of $70 \%$ or more were selected from the 13 and advanced to $\mathrm{BC}_{2} \mathrm{~F}_{1}$ generation (Table 1). Simulation research shows that employing less dense markers in an early $B C$ generation can result saving in excess of $50 \%$ in the number of required marker data points when compared with using a constant set of markers [29].

\subsubsection{Genotyping $B C_{2} F_{1}$ generation}

In genotyping $\mathrm{BC}_{2} \mathrm{~F}_{1}$ generation for $\mathrm{MAS}$, we used 194 plants confirmed to have the introgression of Saltol using AP3206F and RM10748 from a total of 218 plants. Of these 194 plants, 130 ILs had fixed Saltol locus while 64 were heterozygous based on the two foreground markers. Recombinant selection was carried out using heterozygous flanking markers specific to the $5 \mathrm{BC}_{2} \mathrm{~F}_{1}$ populations produced from the 5 best plants of the $\mathrm{BC}_{1} \mathrm{~F}_{1}$ generation (sub section 3.1.1). There were 14 selected individuals that were further used for background selection using 20 heterozygous markers. MAS is expected to cause a preservation of two BC generations [25]. We obtained ILs with recipient allele's genomic composition ranging between 80 to $92 \%$ in 7 plants (P45-19, P45-39, P61-13, P61-6, P73-3, P101-4 and P101-8) (Supplementary Fig. 2). 
These $7 \mathrm{BC}_{2} \mathrm{~F}_{1}$ plants were used to develop $\mathrm{BC}_{3} \mathrm{~F}_{1}$ generation. The number of $\mathrm{BC}$ generations required for the introgression of one target QTL is expected to reduce by two to four backcross generations, depending on the genetic differences between the recurrent and donor parents [30].

\subsubsection{Genotyping $B C_{3} F_{1}$ generation}

Sixty-four $\mathrm{BC}_{3} \mathrm{~F}_{1}$ plants were genotyped for both foreground and recombinant selection of which seven plants were selected and used for background selection with 20 markers (Supplementary Fig. 3). After two generations of recombinant selection, it is likely that the genotypes of markers used as recombinant selection may be fixed to homozygote to the recurrent parent and therefore relatively higher number should have been selected instead of 7 individual plants. This result could be due to the fact that we focused our selection on only clear and contrasting bands that have the introgression of the Saltol allele and bands that were not clear were discarded even though some were showing the introgression. In addition, some seed showing clear bands for the introgression of the Saltol allele were lost or did not germinate and were therefore discarded.

Two plants (P45-39-1 and P61-6-29) with more than 95\% recipient alleles were selected and advanced to $\mathrm{BC}_{3} \mathrm{~F}_{2}$. There were $2380 \mathrm{BC}_{3} \mathrm{~F}_{2}$ seeds produced and used for screening of salt tolerance. Previous research has shown that a sufficiently high proportion of the recurrent genome can be recovered after 2 or 3 generations of marker-based background selection [31]. It has also been indicated that background selection is more efficient in late $B C$ generations than in early BC generations [32]. We therefore used the 151 polymorphic background SSR 
markers to finally genotype $80 \mathrm{ILs}$ at $\mathrm{BC}_{3} \mathrm{~F}_{3}$ (supplementary Table 2). The use of 24 markers on chromosome 1 which were outside the Saltol region was enough to provided adequate information to select introgression lines with minimal donor background. In a similar research, between 7 and 13 markers on chromosome 1 were successfully used to select introgression lines with minimal donor background $[33,34]$. When we consider map distances between markers as the basis for estimating the extent of allele's introgressed from each of the parent in the ILs, it can be observed that the recurrent parent had the longest distance of $102.2 \mathrm{Mb}$, while the donor distance was $13.6 \mathrm{Mb}$ (fig. 3 and supplementary fig. 1). On average, $81 \%$ of the recurrent parent genome alleles were noted in the ILs, while the donor parent genome had 11.5. These results demonstrated the effectiveness of MAS to breed salt tolerant version of a popular cultivar in a short period.

The results of the experiment indicate that we achieved a faster recovery of the recurrent parent genome of 'Rassi' within 3 to 4 seasons (2009-2011) with combined foreground, recurrent and background selection in the Sahelian region of West Africa. The conventional backcrossing takes up to 7 to 10 years. Hence, the use of DNA markers can lead to considerable time saving vis-à-vis the conventional backcrossing approach $[10,14,30]$

\subsection{Validation of Saltol-ILs at vegetative stage}

We used 3 cycles of backcrossing with selection based on marker information and field evaluation between the donor source and the widely grown recurrent parent. These cycles of backcrossing enabled selecting offspring for further advancement based not only on foreground markers homozygous for Saltol, but also on phenotype (SES scores 1 and 3). It has often been 
shown that not all introgressions identified by DNA markers are phenotypically expressed due to many genic, genomic shocks and interlocus interactions such as epistasis, in addition to environmental effects.

Rice is most sensitive to salt stress at the early seedling stage (1-3 weeks) of crop development with a threshold as low as an ECe of $3 \mathrm{dSm}^{-1}$ [35]. In our experiments, $2380 \mathrm{BC}_{3} \mathrm{~F}_{2}$ Saltol-ILs were screened in three batches together with their parents at a high salt level $\left(E C e=12 \mathrm{dSm}^{-1}\right)$. This high concentration permitted the evaluation of how the Saltol-ILs reacts to high salt stress (Fig 2.) The high SES scores reflected the effects of salt stress (Fig. 4a and Fig. $4 b$ ). The $\mathrm{BC}_{3} \mathrm{~F}_{2}$ Saltol-ILs had on average a 3.5 SES score, while the recurrent parent had 4.7 and the donor parent (which also doubles as the tolerant check) had 3.1. The data confirmed the phenotypic differences between the tolerant and sensitive Saltol-ILs as well as with their parental lines. The tolerant Saltol-ILs had low SES scores (1-3) (Fig. 4b). Most of the ILs (1738 or 58.9\%) had an SES score of 3, while 949 having an SES score of at least 5 were discarded. Similar findings about the variability in salt tolerance among rice cultivars at vegetative stage were previously reported [36]. Al Amin et al. [37] observed wide variation by using the SES system to classify 28 accessions from various sources. Likewise, a screening of 5000 M4 rice mutant lines from 'IR64' using the SES classification system led to identifying 935 mutant as tolerant; which were further advanced for screening at the reproductive stage. There were 35 and 8 mutants better than or as sensitive to IR64, respectively [38].

There were $429 \mathrm{BC}_{3} \mathrm{~F}_{2}$ Saltol-ILs (14.5\%) rated as highly tolerant (SES score $=1$ ) (Fig. 4b) of which 80 Saltol-ILs were selected for further advancement to produce the $\mathrm{BC}_{3} \mathrm{~F}_{3}$ after background selection (Supplementary Fig. 1). 


\subsubsection{Adaptation of Saltol ILs to salt stress at reproductive stage under field condition}

Adaptation to salt stress at vegetative and reproductive stages are independent of each other [35], which suggests that adaptation at these two stages could be regulated by different sets of genes [4]. Saltol QTL is only effective at the vegetative stage in rice. Discovering and combining suitable tolerance traits for both stages is essential for developing better salt tolerant cultivars. The best $\mathrm{BC}_{3} \mathrm{~F}_{3}$ Saltol-ILs that are tolerant to salt stress at the vegetative stage $(\mathrm{SES}$ score $=1$ ) were subjected to reproductive stage stress under natural field conditions to help identifying Saltol-ILs with adaptation to salt stress at both vegetative and reproductive stages. We initially subjected $500 \mathrm{BC}_{3} \mathrm{~F}_{3}$ Saltol-ILs to higher salt stress under natural field conditions during the 2011-2012 wet seasons. This screening was done to reduce the number of Saltol-ILs for subsequent field evaluation in the next season. The average ECe of the soil during the growing season was about $5.65 \mathrm{dS} \mathrm{m}^{-1}$.

No Saltol-ILs was observed to have an SES score of 1 , which indicates the high salt concentration under which the experiment was conducted (Fig. 5). There were 158 Saltol-ILs with SES score of 3, while the remaining had SES score above 5. The effectiveness of using SES scores to classify rice breeding lines into both tolerant and sensitive was shown elsewhere [37]. Mishra et al. [39] rated different cultivars at the reproductive stage using the SES system as tolerant and sensitive after screening 16 different accessions under controlled conditions. The tolerant 'IR64' rice mutants had significantly lower SES scores (4.0 vs. 7.0) and better survival and growth than either IR64 or the sensitive mutants under saline fields [38]. 
Highly significant differences $(P<0.0001)$ were observed for all traits in ILs (Table 2$)$. Grain yield ranged from $109 \mathrm{~g} \mathrm{~m}^{-2}$ to $985 \mathrm{~g} \mathrm{~m}^{-2}$ under non salt stress; while number of tillers varied, on average, between 10.3 to 32.8 . Only 1000 -grain weight was significantly different among the ILs and the recurrent parents $(P<0.0001)$, while significant difference were observed for all traits between the donor parent ('FL478') and ILs. This result confirms that the ILs in addition to being salt-tolerant at the vegetative stage have most traits of 'Rassi'. Early work on the introgression of submergence tolerant QTL Sub1 into Swarna, showed that submergence tolerant plants possessing Swarna-type plant in addition to the Sub1 locus became available in the $\mathrm{BC}_{2} \mathrm{~F}_{2}$ generation [10]. Similarly, Koshihikari rice-type of plants was noted after introgressing different heading date QTL into this cultivar [40]. These results showed that 'Rassi' could be efficiently converted to a salt tolerant cultivar both at early seedling and reproductive stages after 3 backcross generations; i.e., 2 to 3 years.

\subsubsection{Effect of salt stress on grain yield}

The ECe of the non-salt field was less than $1 \mathrm{dS} \mathrm{m}^{-1}$ whilst that of the salt field ranged between 6.5 and $9.5 \mathrm{dS} \mathrm{m}^{-1}$. The variation between tolerant and sensitive ILs was expressed under natural salt field conditions. Variances due to genotypes (G), genotype $\times$ salt stress levels (G×E) and genotype $\times$ salt stress levels $\times$ seasons $(G \times E \times Y)$ interactions were significantly different $(P<$ 0.05 ) for all traits except numbers of grains per panicle, panicle $\mathrm{m}^{-2}$ and tillers per plant (for the $\mathrm{G} \times \mathrm{E} \times \mathrm{Y}$ ) and 1000-seed weight and number of panicles $\mathrm{m}^{-2}$ (for the $\mathrm{G} \times \mathrm{E}$ ) (Table 3). Salt stress generally had major effects on the performance of the ILs for all traits, thus causing grain yield reduction among the ILs in excess of $50 \%$ under stress $\left(251.12 \mathrm{~g} \mathrm{~m}^{-2}\right.$ versus $543.22 \mathrm{~g} \mathrm{~m}^{-2}$ recorded in non-stress fields) even though some ILs were less affected (16 to $25 \%$ ). Grain yield 
loss of $13 \%$ to $77 \%$ under salt stress has been recorded in other experiments [38, 41$]$. Bimpong et al. [41] observed that salt stress could cause trait reduction in rice under field screening of large populations of $\mathrm{F}_{2}$-derived offspring; e.g. grain yield loss was very high ranging between $65 \%$ and $73 \%$. There was a wide range for grain yield in the ILs when grown under salt stress. Some of them showed better grain yield than the recurrent parent $\left(660.46 \mathrm{~g} \mathrm{~m}^{-2}\right.$ versus 139.53 $\mathrm{g} \mathrm{m}^{-2}$, respectively).

The ILs had a lower grain yield loss than their recurrent parent (73.6\%; 139.53 and $527.59 \mathrm{gm}^{-2}$ ) under stress and non-stress respectively but similar to the donor ' $F L 478$ ' (50.1\%) whose grain yields were $238.45 \mathrm{~g} \mathrm{~m}^{-2}$ under stress and $477.52 \mathrm{~g} \mathrm{~m}^{-2}$ under non-stress. This result shows the high sensitivity of the recurrent parent 'Rassi' (74\% grain yield loss) to salt stress. Grain yield losses of $69 \%$ were observed for sensitive cultivars whereas tolerant lines produced about $63 \%$ higher grain yield than recurrent parents [38]. Adverse effects of salt stress on grain yield and yield components have been reported with an ECe level as low as $3.4 \mathrm{dS} \mathrm{m}^{-1}$ in the arid Sahelian dry seasons where our research was also conducted [5]. A high temperature and rainfall after flowering affect grain yields.

Our finding shows that low yielding 'FL478' bears alleles that are likely to significantly improve grain yield under salt stress, thereby suggesting transgressive segregation that could result from the accumulation of favorable alleles. Thomson et al. [16] found wide transgressive segregation after using 'FL478' as a donor and indicated that additional alleles from the donor parent were involved. About $10 \%$ of the 116 ILs showing minimal grain yield loss (3-26\%) were rated as tolerant (Table 4). This results shows that the Saltol ILs not only possess tolerance to salt stress at the vegetative stage but in addition have high grain yield potential and also tolerance to salt 
stress at the reproductive stage. The tolerant ILs with high grain yield potential is also candidates for further research to identify the genes associated with salt tolerance at the reproductive stage.

\subsubsection{Effect of salt stress on agronomic traits}

We observed a lesser reduction in agronomic traits measured in tolerant Saltol-ILs than in susceptible ILs. For instance some of the tolerant Saltol ILs had plant height reduction below $20 \%$ under salt stress compared to as high as $38 \%$ among sensitive lines (Table 3 ). This result agrees with previous research indicating that an increase in salt stress level causes a reduction in plant height of rice [37]. Salt stress could inhibit cell division directly or indirectly, thus resulting in the leaves and stems of the affected plants becoming stunted [42]. The effect of salt stress caused a $12.4 \%$ decrease in number of tillers in Saltol-ILs. A decrease of 15 to $40 \%$ was noted before under salt stress [5]. Reduction in number of days to flowering and plant height was comparable among the ILs and the two parents. The recurrent parent 'Rassi' under salt stress flowered approximately 2 days earlier than in fields with no stress. The ILs and the two parents also increased their percentage of panicle sterility under stress.

\subsubsection{Correlation of yield and other traits}

Adaptation for tolerance to salt stress is known to be a function of a various plant attributes; hence any breeding line exhibiting relative salt stress tolerance for all relevant plant attributes may be ideal for using as trait sources in a breeding scheme or to release as cultivar per se [43]. We observed that yields in the saline environment were consistently lower than yields in nonsaline conditions (Fig. 6). There was a strong and significant association $\left(R^{2}=0.43\right)$ between grain yields under stress and non-stress. Furthermore, eight Saltol-ILs (IL41, IL58, IL65, IL63; IL68, 
IL71, IL73 and IL106) had grain yield equal to or better than the mean yield of the trial under both salt stress and non-stress, and were also higher yielding than their two parents. These 8 Saltol-ILs are thus good candidates for advancement in breeding programs for both salt and non-salt environments.

Very few experiments evaluated tolerance to salt stress at early seedling stage, continued it to reproductive stage, and quantified the effect of salt stress on grain yield in rice. In one study, the authors observed a wide cultivar difference on salt stress tolerance, and identified one tolerant cultivar at both early seedling and reproductive stages [44]. Higher grain yields was observed for some rice genotypes under saline coastal field conditions than their parents [38]. Some of these genotypes also had high grain yield and harvest index under non-stress. The observation in our study suggests that in addition to Saltol QTL, some other positive alleles have been transferred to them from the low-yielding donor parent 'FL478'. Beneficial alleles from low-yielding cultivars and wild rice species increased grain yield of rice under abiotic stress, such as salt $[36,41]$, submergence [10] and drought [45]. The effect of salt stress is also reflected on their correlations with grain yield under salt stress, especially with panicle $\mathrm{m}^{-2}$ and grains per panicle $(r=0.53), 1000$-grain weight $(r=0.17)$ and panicle sterility $(r=-0.21)$, thus suggesting the importance of this growth and grain yield traits under salt stress (Table 5).

\section{Conclusion}

Genomic tools are opening the doors for the utilization of elite germplasms endemic to SubSahara Africa (SSA) as many elite lines developed outside Africa are inaccessible due to lack of adaptation (diseases, pest resistances, tolerance to problem soils including salt stress). The use of MAS enabled us to rapidly introgress Saltol into an elite cultivar which is a well-adapted 
West Africa popular variety (Rassi) and field tested in a shorter span of time from 4-5 years (2009-2014) compared to traditional backcrossing which can take up to 7- 10 years which will help contribute to food security in Africa.

More than 400 Saltol-ILs were identified as tolerant to salt stress at early seedling stage (SES score of 1.0) which will be beneficial to African resources poor farmers whose fields are prone to early seedling loss due to the direct seeding nature they practice.

Compared to Asia and elsewhere, similar studies have been conducted but in all using Asian varieties to introgress Saltol, but to the best of our knowledge, this is the first successful example of using MAS for rice breeding in SSA where by using a cultivar which is well adapted under African conditions.

All the MAS conducted using Saltol are only adaptable to salt stress at the seedling stage, besides very few experiments have evaluated tolerance to salt stress at early seedling stage and continued to reproductive stage; in the current study, we tested 116 ILs that showed tolerance to salt stress at the early seedling stage and also have minimum donor alleles under natural field conditions for 4 seasons where the salt level varies between ECe of 6.5 and $9.5 \mathrm{dS} \mathrm{m}^{-1}$ and identified 16 Saltol -ILs with relatively less yield penalty of $3-26 \%$. These ILs will be very beneficial to farmers in SSA and beyond where salt stress occurs throughout the growing period of the rice crop.

The identified ILs with strong adaptation to SSA environmental conditions may not suffer salt stresses compared to introduction of elite germplasms into Africa which are not adaptable.

Eight of the 16 Saltol -ILs (IL41, IL58, IL65, IL63; IL68, IL71, IL73 and IL106) identified to have grain yields similar to or better than the average yield of the trials under both salt and non- 
stress conditions; may have attained high yielding potential in addition to tolerance to salt stress and will be suitable also for non -salt stress lowland and other rice growing ecologies such as irrigated, mangrove swamp and deep-water systems.

Seeds of 16 Saltol -ILs nominated into the African wide Rice breeding taskforce have been produced and disseminated to 6 WA countries (The Gambia, Guinea-Bissau, Guinea Conakry, Nigeria, Senegal and Sierra Leone) for field testing during the 2014-2015 wet season. These are expected to enhance rice productivity under both rainfed lowland and irrigated conditions and help contribute to food production.

Acknowledgement Authors are grateful to technical staff members of AfricaRice and IRRI for their contribution in the implementation of the experiments. Financial support for Salt tolerance research at AfricaRice was provided by the project Stress-Tolerant Rice for poor farmers in Africa and South Asia (STRASA) funded by the Bill and Melinda Gates Foundation. 


\section{References}

[1] F. Lançon, O. Erenstein, Potential and prospects for rice production in West Africa. In: SubRegional Workshop on Harmonization of Policies and Coordination of Programmes on Rice in the ECOWAS Sub-Region, Accra, Ghana, 25-28 February 2002. Bouake, Côte d'Ivoire: West Africa Rice Development Association. http://www.hubrural.org/IMG/pdf/potential-andprospects-for-rice-production-wa.pdf

[2] US Salinity Laboratory Staff, United States Salinity Laboratory Staff, Diagnosis and improvement of saline and alkali soils. US Department of Agriculture, Agricultural Handbook No. 60. US Government Printer, Washington, DC, 1954.

[3] A. Diagne, D.Y. Alia, E. Amovin-Assagba, M.C.S. Wopereis, K. Saito, T. Nakelse; Farmer perception of Biophysical constraints to rice production in sub-saharan Africa, and potential impact of research. in: M.C.S. Wopereis, D.E. Johnson, N. Ahmadi, E. Tollens, A. Jalloh (eds.), Realizing Africa's rice promise 2013, pp. 46-68.

[4] F. Moradi, A. M. Ismail, G. B. Gregorio, J. A. Egdane, Salinity tolerance of rice during reproductive development and association with tolerance at the seeding stage. Indian J. Plant Physio 8, (2003) 105-116

[5] T. J. Flowers, A. R. Yeo, Breeding for salinity resistance in crop plants-where next? Aust. J. Plant Physiol. 22 (1995) 875-884.

[6] M. Hossain, D. Gollin, V. Cabanilla, E. Cabrera, N. Jonson, G.S. Khush, G. McLaren, International research and genetic improvement and its effect on productivity: the impact of 
international agricultural research. In: RE Evenson, D Gollin, (Eds.), Crop variety improvement and its effect on productivity: the impact of international agricultural research. Wallingford, Oxon, United Kingdom: CABI, 2003, pp 71-107

[7] M. Delseny, Towards an accurate sequence of the rice genome: Curr. Opin. Plant Biol. (2003) 6: 101-5.

[8] L. B. Guo, G. Y. Ye, Use of major quantitative trait loci to improve grain yield of rice. Rice Science 21(2014) 174-178.

[9] P. H. Zhou, Y. F. Tan, Y. Q. He, C. G. Xu, Q. Zhang, Simultaneous improvement for four quality traits of Zhenshan 97, an elite parent of hybrid rice, by molecular marker-assisted selection, Theor Appl Genet , 106 (2003) 326-331.

[10] C. N. Neeraja, R. Maghirang-Rodriguez, A. Pamplona, S. Heuer, B.C. Collard, E.M. Septiningsih, G. Vergara, D. Sanchez, K. Xu, A.M. Ismail, D.J. Mackill, A marker-assisted backcross approach for developing submergence-tolerant rice cultivars, Theor Appl Genet , 115 (2007) 767-776.

[11] P. Bonilla, J. Dvorak, D. Mackill, K. Deal, G. Gregorio, RFLP and SSLP mapping of salinity tolerance genes in chromosome 1 of rice (Oryza sativa L.) using recombinant inbred lines, Philippine Agricultural Scientist, 65 (2002) 68-76.

[12] G. B. Gregorio, M. R. Islam, G. V. Vergara, S. Thirumeni, Recent advances in rice science to design salinity and other abiotic stress tolerant rice varieties. SABRAO Journal of Breeding and Genetics 45 (2013) $31-41$. 
[13] G. B. Gregorio, D. Senadhira, R. D. Mendoza, Screening rice for salinity tolerance. IRRI Disc. Paper Series 22 (1997) 1-30

[14] B. C. Y. Collard, D. J. Mackill, "Marker-assisted selection: an approach for precision plant breeding in the twenty-first century," Philosophical Transactions of the Royal Society B, 363 (2008) 557-572.

[15] S. L. Dellaporta, J. Wood, J. B. Hicks, A plant DNA minipreparation: Version II. Plant Mol. Bio Reporter 4 (1983)19-21.

[16] M. J. Thomson, M. de Ocampo, J. Egdane, M.A Rahman, A.G. Sajise, D.L. Adorada, E. Tumimbang-Raiz, E. Blumwald, Z.I. Seraj, R.K. Singh, G.B. Gregorio, A.M. Ismail, Characterizing the saltol quantitative trait locus for salinity tolerance in rice," Rice (2010) 1-13.

[17] S. Temnykh, G. DeClerck, A. Lukashova, L. Lipovich, S, Cartinhour, S, McCouch, Computational and experimental analysis of microsatellites in rice (Oryza sativa L.): frequency, length variation, transposon associations and genetic marker potential. Genome Res, 11 (2001) $1441-1452$

[18] J.H. Chin, J.H. Kim, S.W. Kwon, Y.I. Cho, Z.Z. Pia, L.Z. Han, H.J. Koh, Identification of subspecies specific RAPD markers in rice, Korean J. Breed. 35 (2003) 102-108.

[19] G.B. Gregorio, Tagging salinity tolerance denes in rice using amplified fragment length polymorphism (AFLP). Univ. Philippines, Los Baños, Philippines, 1997, p 118 
[20] R.K. Singh, T.J. Flower, The physiology and molecular biology of the effect of salinity on rice. In: Pessarakli M. (ed.), Handbook of plant and crop stress, $3^{\text {rd }}$ edition, Taylor and Francis, Boca Raton, Florida, USA 2011, pp.899-986.

[21] IRRI, Standard evaluation system for rice, fourth ed. International Rice Research Institute, Los Baños, Philippines, 1996

[22] SAS Institute Inc, SAS/STAT ${ }^{\circledR} 9.2$ User's Guide. Cary, North Carolina: SAS Institute Inc. 2004

[23] F. Hospital, Marker-assisted breeding. In: H.J. Newbury (ed.), Plant molecular breeding Blackwell Publishing and CRC Press, Oxford and Boca Raton, 2003, pp. 30-59.

[24] Z. I. Seraj, A.M. Ismail, M. J. Thomson, Md. S. Rahman, Enhancing capacity for use of advance genotyping for fine-mapping and pyramiding of major salt tolerant QTLs through $M A B C$ for the development of durable saline tolerant rice varieties; Final Technical Report to Generation Challenge program, (GCP Project No: SP5- G4010.04) 2011, pp. 1-17

[25] F. Hospital, C. Chevalet, P. Mulsant, Using markers in gene introgression breeding programs. Genetics 132 (1992) 1199-1210.

[26] Visscher P.M. Proportion of the variation in genetic composition in backcrossing programs explained by genetic markers. J. Heredity 87 (1996) 136-138

[27] B. Servin, F. Hospital, Optimal positioning of markers to control genetic background in marker-assisted backcrossing. J Heredity 93 (2002) 214-217 
[28] E.M. Septiningsih, A.M. Pamplona, D.L. Sanchez, C.N. Neeraja, G.V. Vergara, S. Heuer, A.M. Ismail, D.J. Mackill, Development of submergence tolerant rice cultivars: The Sub1 locus and beyond. Ann. Bot.103 (2009)151-160.

[29] V. Prigge, A.E. Melchinger, B. S. Dhillon, M. Frisch, Efficiency gain of marker-assisted backcrossing by sequentially increasing marker densities over generations; Theor Appl Genet 119 (2009) 23-32.

[30] M. Frisch, M. Bohn, A.E. Melchinger, Comparison of selection strategies for marker-assisted backcrossing of a gene. Crop Sci. 39 (1999) 1295-1301.

[31] S.D. Tanksley, N.D. Young, A.H. Paterson, M.W. Bonierbale, RFLP mapping in plant breeding: new tools for an old science. Bio. Technology 7 (1989) 257-263.

[32] J.M. Ribaut, C. Jiang, D. Hoisington, Simulation experiments on efficiencies of gene introgression by backcrossing, Crop Sci. 42 (2002) 557-565.

[33] M. Thomson, M. A. Rahman, M.A. Salam, Z.I. Seraj, M. M. Islam, T. Paris, R.K. Singh, A. M. Ismail, Marker-assisted backcrossing for improved salt Notes: tolerance in rice. Poster presentation at Generation challenge program (GCP) annual research meeting impact pathway, Bangkok, Thailand.16-20 September 2008 pp43

[34]. Seraj et al 2008 Z. I. Seraj; M. S. Rahman, M. R. Islam, T. Kaque, S. Rahman, N. Begum; Improvement of Mega Rice varieties BR11 and BRRI dhan28 by introgression of the Saltol Loci using marker-assisted selection. Poster presentation Generation challenge program (GCP) annual research meeting, Bangkok, Thailand.16-20 September 2008, pp36 
[35] R.K. Singh, K.N. Singh, B. Mishra, S.K. Sharma, N.K. Tyagi, Harnessing plant salt tolerance for overcoming sodicity constraints: an Indian experience: Advances in Sodic Land Reclamation, Proc Intl Conf Sustainable Management of Sodic Soils, Lucknow, India, 2004, pp 81-120.

[36]. I.K. Bimpong , B. Manneh, R. Namaky , F. Diaw , N.K.A. Amoah, B. Sanneh , K. Ghislain , A. Sow , R.K. Singh , G. Gregorio , J. B. Bizimana , M. Wopereis, Mapping QTLs Related to Salt Tolerance in Rice at the Young Seedling Stage using 384-plex Single Nucleotide Polymorphism SNP, Marker Sets, Mol. Plant Breed. 5 (2014) 47-63.

[37] M. Al-Amin, M.M. Islam, S.N. Begum, M.S. Alam, M. Moniruzzaman, M.A.K. Patwary, Evaluation of rice germplasm under salt stress at the Seedling stage through SSR markers, Int. J. Agril. Res. Innov. \& Tech., 3 (2013) 52-59.

[38] B. Nakhoda, H. Leung, M.S. Mendioro, G. Mohammadi-nejad, A.M. Ismail, Isolation, characterization, and field evaluation of rice (Oryza sativa L., var. IR64) mutants with altered responses to salt stress. Field Crops Res.127 (2012) 191-202.

[39] V. K. Mishra, D. K. Dwivedp, S. Kumar 0. P. Verma, Screening for Salinity Tolerance at Vegetative and Reproductive Stages in Rice (Oryza saliva L.) Environment \& Ecology 30:2 (2012) $355-360$.

[40] Y. Takeuchi, Ebitani , T. Yamamoto, H. Sato, H. Ohta, H. Hirabayashi, H. Kato, I. Ando, H. Nemoto, T. Imbe, M. Yano. Development of isogenic lines of rice cultivar Koshihikari with early and late heading by marker-assisted selection. Breed Sci. 56 (2006) 405-413 
[41] I.K. Bimpong, B. Manneh, B. Diop, K. Ghislain, A. Sow, N.K.A. Amoah, G. Gregorio, R.K. Singh, R. Ortiz, M. Wopereis, New quantitative trait loci for enhancing adaptation to salinity in rice from Hasawi, a Saudi landrace into three African cultivars at the reproductive stage, Euphytica 200 (2014) 45-60.

[42] R. Munns, M. Tester, Mechanisms of salinity tolerance. Annu. Rev. Plant Biol., 59 (2008) 651-681.

[43] L. Bernstein, Physiological basis of salt tolerance in plants, Basic Life Sci. 8 (1977) 283-290.

[44] L. Zeng, M.C. Shannon, C. M. Grieve. Evaluation of salt tolerance in rice genotypes by multiple agronomic parameters. Euphytica, 127 (2002) 235-245.

[45] I.K. Bimpong, R. Serraj, J.H. Chin, J. Ramos, E.T.M Mendoza, J. Hernandez, M.S. Mendioro, D.S. Brar, Identification of QTLs for Drought-Related Traits in Alien Introgression Lines derived from crosses of Rice (Oryza sativa cv IR64) x O. glaberrima under Lowland drought stress J. Plant Bio.54 (2011) 237-250. 
Table 1.Proportion of recurrent parent alleles from $13 \mathrm{BC}_{1} \mathrm{~F}_{1}$ recombinant lines and best 5 introgression lines selected for advancement

\begin{tabular}{|c|c|c|c|c|c|c|c|c|c|c|c|c|c|}
\hline No: & 1 & 2 & 3 & 4 & 5 & 6 & 7 & 8 & 9 & 10 & 11 & 12 & 13 \\
\hline $\begin{array}{c}\text { Original plant } \\
\text { No: }\end{array}$ & 11 & 28 & 45 & 61 & 64 & 65 & 73 & 78 & 88 & 96 & 99 & 101 & 130 \\
\hline $\begin{array}{c}\text { A (Recipient } \\
\text { allele) }\end{array}$ & 54.50 & 47.40 & 60.0 & 57.1 & 42.90 & 42.9 & 42.10 & 27.30 & 30.40 & 30.40 & 22.70 & 54.50 & 52.10 \\
\hline \begin{tabular}{c} 
Heterozygous \\
\hline $\begin{array}{c}\text { Percent } \\
\text { recipient } \\
\text { allele (R\%)* }\end{array}$
\end{tabular} & 27.30 & 31.50 & 30.0 & 33.3 & 42.90 & 42.9 & 52.60 & 68.40 & 30.40 & 39.10 & 31.80 & 36.40 & 34.80 \\
\hline
\end{tabular}

* Percent recipient allele $=$ the proportion of alleles from the recurrent parent genome observed in the progeny after background selection with a specific amount of molecular markers

Numbers in bold = Plant numbers selected for advancement 
Table 2. Agronomic performance of $B C_{3} F_{4}$ Saltol introgression lines and the parents under non saline control in 2011-2012DS

\begin{tabular}{|c|c|c|c|c|c|c|c|}
\hline Genotypes & $\begin{array}{c}\text { Grain Yield } \\
\left(\mathrm{gm}^{-2}\right)\end{array}$ & $\begin{array}{l}\text { 1000-Seed } \\
\text { Weight (g) }\end{array}$ & $\begin{array}{c}\text { Number of } \\
\text { grains/Panicle }\end{array}$ & Panicle/meter-2 & $\begin{array}{c}\text { Tiller } \\
\text { Number/plant }\end{array}$ & $\begin{array}{c}\text { Days to } \mathbf{5 0 \%} \\
\text { Flowering(days) }\end{array}$ & $\begin{array}{c}\text { Plant Height } \\
(\mathrm{cm})\end{array}$ \\
\hline Rassi(RP) & $689.1( \pm 44.4)$ & $27.1( \pm 0.1)$ & $62( \pm 5.7)$ & $439( \pm 71.6)$ & $21( \pm 1.3)$ & $96( \pm 1.4)$ & $96.8( \pm 2.4)$ \\
\hline FL478(Donor) & $430.1( \pm 36.7)$ & $24.5( \pm 0,7)$ & $51( \pm 2.1)$ & $354( \pm 12.3)$ & $18( \pm 1.9)$ & $86( \pm 0)$ & $74.1( \pm 1.8)$ \\
\hline ILs & $697.1( \pm 200.6)$ & $21.3( \pm 1.2)$ & $49( \pm 16.9)$ & $470( \pm 98.1)$ & $21( \pm 3.6)$ & $95( \pm 2.2)$ & $101.96( \pm 6.9)$ \\
\hline Range_ILs & 109.2 - 984.7 & $20-26.2$ & $20-106$ & $18.8-787.5$ & $10.3-32.8$ & $88-98$ & $82.8-126.8$ \\
\hline $\operatorname{LSD}_{(0.05)}$ & 25.97 & 0.18 & 2.19 & 12.81 & 0.47 & 0.29 & 1.03 \\
\hline ILs - Rassi & ns & $* * *$ & ns & ns & ns & ns & ns \\
\hline ILs - FL478 & *** & *** & *** & $* * *$ & $* * *$ & *** & *** \\
\hline
\end{tabular}

Numbers in parenthesis are standard deviation values, $n s=$ No significant difference, ${ }^{* * *}=$ Significant difference at $P<.0001$ among ILs, Rassi and/or FL478

$R P=$ recurrent parent 
Table 3. Combined analysis of grain yield $\left(\mathrm{gm}^{-2}\right)$ and other yield related traits of Saltol Introgression lines $\left(B C_{3} F_{5}\right.$ and $\left.B C_{3} F_{6}\right)$ and their parents in salt and non -salt stress conditions: Ndiaye, Senegal 2012- 2013 WS and 2013-2014DS

\begin{tabular}{|c|c|c|c|c|c|c|c|c|}
\hline Genotype & $\begin{array}{l}\text { Grain Yield (gm- } \\
\text { 2) }\end{array}$ & $\begin{array}{l}\text { 1000-Seed } \\
\text { Weight (g) }\end{array}$ & $\begin{array}{l}\text { Number of } \\
\text { grains / Panicle }\end{array}$ & $\begin{array}{l}\text { Percent } \\
\text { Panicle } \\
\text { Sterility (\%) }\end{array}$ & Panicle/meter-2 & $\begin{array}{l}\text { Tiller } \\
\text { Number / } \\
\text { plant }\end{array}$ & $\begin{array}{l}\text { Days to } 50 \% \\
\text { Flowering } \\
\text { (days) }\end{array}$ & $\begin{array}{l}\text { Plant Height } \\
\text { (cm) }\end{array}$ \\
\hline \multicolumn{9}{|l|}{$\begin{array}{l}\text { Non } \\
\text { Stress }\end{array}$} \\
\hline Rassi & $527.59( \pm 115.6)$ & $28.2( \pm 1.3)$ & $24.28( \pm 20.1)$ & $18.83( \pm 21.9)$ & $474.37( \pm 302.3)$ & $18.65( \pm 3.2)$ & $94.4( \pm 5.1)$ & $93.9( \pm 5.9)$ \\
\hline FL478 & $477.52( \pm 92.2)$ & $26.8( \pm 1.3)$ & $25.79( \pm 20.6)$ & $18.39( \pm 13)$ & $432.85( \pm 202.1)$ & $20.65( \pm 6.1)$ & $85.8( \pm 3.0)$ & $99.2( \pm 10.1)$ \\
\hline & $543.22( \pm 176.2)$ & $26.38( \pm 6.4)$ & $47.4( \pm 22.6)$ & $6.83( \pm 6.1)$ & $386.04( \pm 140.9)$ & $18.4( \pm 4.2)$ & $94.34( \pm 5.9)$ & $97.53( \pm 9.9)$ \\
\hline Range_ILs & $113-916.27$ & $15.9-32$ & $4-117$ & $0-43$ & $175-850$ & $10.5-32.75$ & $90-98$ & $75.5-126.75$ \\
\hline $\operatorname{LSD}_{(0.05)}$ & 14.74 & 0.54 & 1.91 & 0.55 & 12.06 & 0.35 & 0.50 & 0.83 \\
\hline \multicolumn{9}{|l|}{ Stress } \\
\hline Rassi & $139.53( \pm 36)$ & $27.83( \pm 0.8)$ & $13.57( \pm 4)$ & $\begin{array}{l}71.57 \\
( \pm 290.5)\end{array}$ & $189.17( \pm 45)$ & $12.96( \pm 5.5)$ & $95.5( \pm 5)$ & $71.92( \pm 12.1)$ \\
\hline FL478 & $238.45( \pm 141)$ & $22.17( \pm 11)$ & $25.58( \pm 17.6)$ & $64.1( \pm 22.9)$ & $274.67( \pm 150.7)$ & $15.33( \pm 5)$ & $84( \pm 7.7)$ & $78.08( \pm 8.3)$ \\
\hline ILs & $251.12( \pm 174.8)$ & $\begin{array}{l}25.79 \\
( \pm 11.5)\end{array}$ & $26.11( \pm 17.6)$ & $34.29( \pm 26.9)$ & $312.31( \pm 178.9)$ & $16.69( \pm 5.9)$ & $\begin{array}{l}90.81 \\
( \pm 17.7)\end{array}$ & $77.63( \pm 15.5)$ \\
\hline Range_ILs & $37.2-660.46$ & $10-34$ & $1-80$ & $0-100$ & $29-850$ & $8.5-34$ & $78-111$ & $55.3-97$ \\
\hline $\begin{array}{l}\mathrm{LSD}_{(0.05)} \\
\text { Percent } \\
\text { mean } \\
\text { Reduction }\end{array}$ & 13.36 & 0.88 & 1.35 & 3.06 & 13.68 & 0.45 & 1.35 & 1.18 \\
\hline Rassi & 73.6 & 1.3 & 44.1 & - & 60.1 & 30.5 & -1.2 & 23.4 \\
\hline FL478 & 50.1 & 17.3 & 0.8 & - & 36.5 & 25.8 & 2.1 & 21.3 \\
\hline ILs & 53.8 & 2.2 & 44.9 & - & 19.1 & 9.3 & 3.7 & 20.4 \\
\hline $\begin{array}{l}\text { Range } \\
\text { ANOVA }\end{array}$ & $1.40-90.76$ & $1.78-86.88$ & $22.46-100$ & & $4.99-93.88$ & $0.29-43.95$ & - & $9.20-31.05$ \\
\hline$G \times E \times Y$ & $0.0073^{* *}$ & $0.0256^{*}$ & $0.0225^{\mathrm{ns}}$ & $<.0001^{* * *}$ & $0.1494^{\mathrm{ns}}$ & $0.3384^{\mathrm{ns}}$ & $<.0001^{* * *}$ & $<.0001^{* * *}$ \\
\hline $\mathrm{G} \times \mathrm{E}$ & $0.0164^{*}$ & $0.1061^{\mathrm{ns}}$ & $0.0084^{* *}$ & $<.0001^{* * *}$ & $0.0682^{\mathrm{ns}}$ & $<.0001^{* * *}$ & $<.0001^{* * *}$ & $<.0001^{* * *}$ \\
\hline $\mathrm{G}$ & $0.0047^{* *}$ & $0.0109 *$ & $0.0027^{* *}$ & $<.0001^{* * *}$ & $0.0032^{* *}$ & $<.0001^{* * *}$ & $<.0001^{* * *}$ & $<.0001^{* * *}$ \\
\hline
\end{tabular}


Table 4. Promising breeding lines identified through screening under saline stress in 2013-2014DS and WS at the Africa Rice Sahel station farms, Ndiaye and Ndiol, Senegal

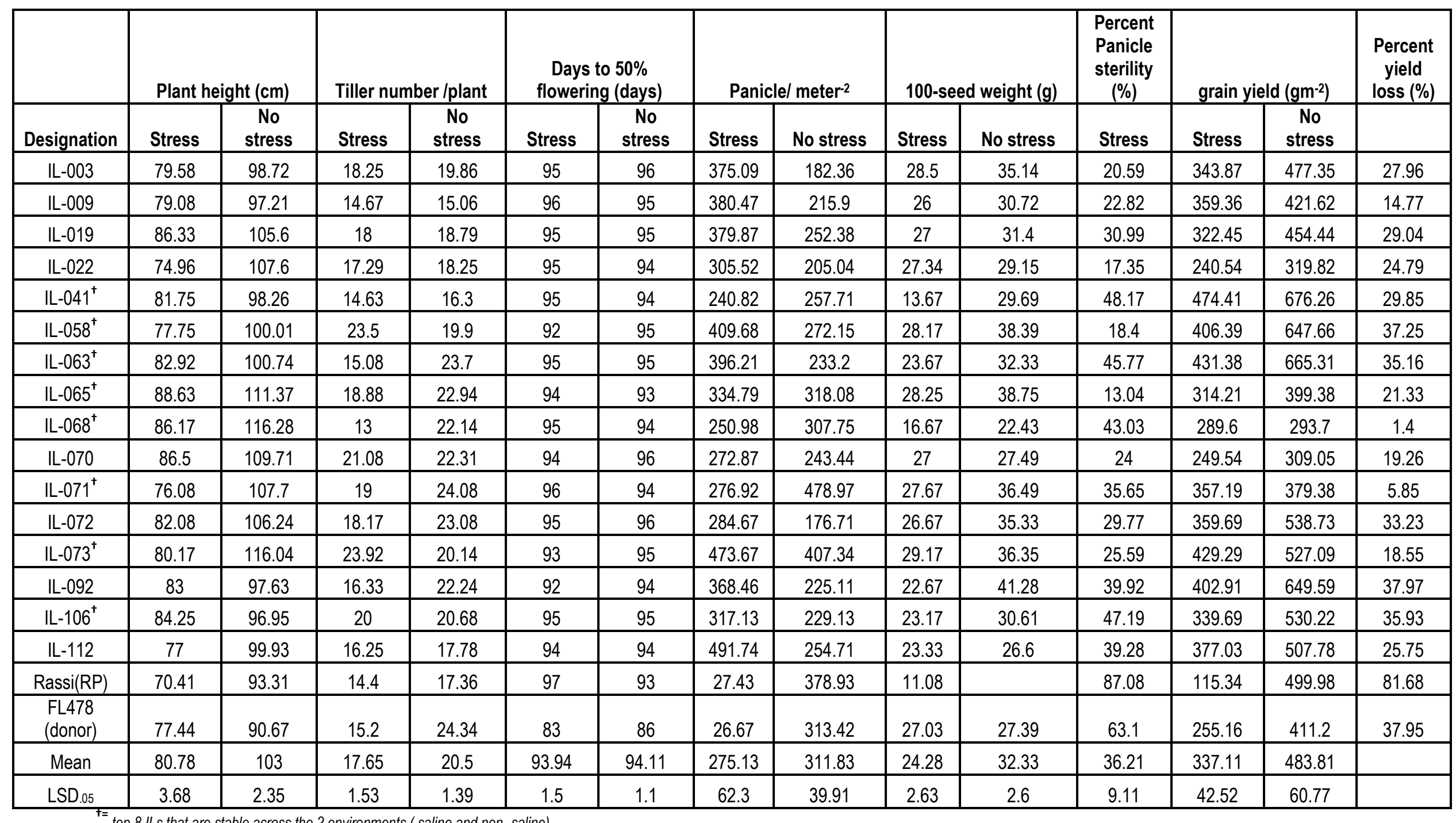

\footnotetext{
$=$ top 8 ILs that are stable across the 2 environments ( saline and non- saline)
} 
Table 5. Phenotypic correlations between 16 best $\mathrm{BC}_{3} \mathrm{~F}_{6}$ ILs selected under salt-stress (i) and non-salt stress (ii) at Ndiaye, Senegal

\begin{tabular}{|c|c|c|c|c|c|c|c|}
\hline (i) Stress conditions & $\begin{array}{l}\text { Plant } \\
\text { Height } \\
(\mathrm{cm}) \\
\end{array}$ & $\begin{array}{c}\text { Tiller } \\
\text { number }\end{array}$ & $\begin{array}{c}\text { Days to } 50 \% \\
\text { Flowering }\end{array}$ & $\begin{array}{c}\text { Panicle sterility } \\
(\%)\end{array}$ & Panicle $/ \mathrm{m}^{2}$ & Grain/panicle & $\begin{array}{c}1000 \text { seed } \\
\text { weight } \\
\text { (g) }\end{array}$ \\
\hline Tiller number & 0.03 & & & & & & \\
\hline Days to $50 \%$ Flowering & 0.06 & 0.1 & & & & & \\
\hline Panicle sterility (\%) & $0.28^{* * *}$ & -0.07 & 0.01 & & & & \\
\hline Panicle/m² & 0.18 & -0.03 & 0.05 & -0.19 & & & \\
\hline Grain/panicle & 0.19 & -0.07 & -0.05 & $-0.38^{* * *}$ & $0.3^{* * *}$ & & \\
\hline $\begin{array}{l}1000 \text { seed weight } \\
\text { (g) }\end{array}$ & -0.01 & 0 & 0 & $0.2^{* * *}$ & 0.15 & 0.02 & \\
\hline Grain yield $\left(\mathrm{gm}^{-2}\right)$ & 0.08 & 0.01 & 0.14 & $-0.21^{* \star *}$ & $0.53^{* * *}$ & $0.53^{* * *}$ & 0.17 \\
\hline \multicolumn{8}{|l|}{ (ii) Non- stress conditions } \\
\hline Tiller number & $0.71^{* \star *}$ & & & & & & \\
\hline Days to $50 \%$ Flowering & 0.06 & 0.07 & & & & & \\
\hline Panicle sterility (\%) & 0.09 & 0.05 & -0.2 & & & & \\
\hline Panicle/m² & $0.21^{* * *}$ & $0.24^{* * *}$ & -0.14 & $0.25^{\star * *}$ & & & \\
\hline Grain/panicle & 0.22 & $0.32^{* * *}$ & $0.24^{* * *}$ & $-0.3^{* \star *}$ & $0.21^{* * *}$ & & \\
\hline $\begin{array}{l}1000 \text { seed weight } \\
\text { (g) }\end{array}$ & 0.03 & -0.05 & 0.06 & -0.06 & -0.09 & 0.02 & \\
\hline Grain yield $\left(\mathrm{gm}^{-2}\right)$ & $0.28^{* * *}$ & $0.32^{\star * *}$ & $0.2^{* * *}$ & 0.12 & $0.49^{* * *}$ & $0.49^{* * *}$ & 0.14 \\
\hline
\end{tabular}

\footnotetext{
${ }^{*}{ }^{* *}$ and ${ }^{* * *}$ indicate significant sources of variation at $P \leq 0.05, P \leq 0.01$ and $P<0.001$,
} 


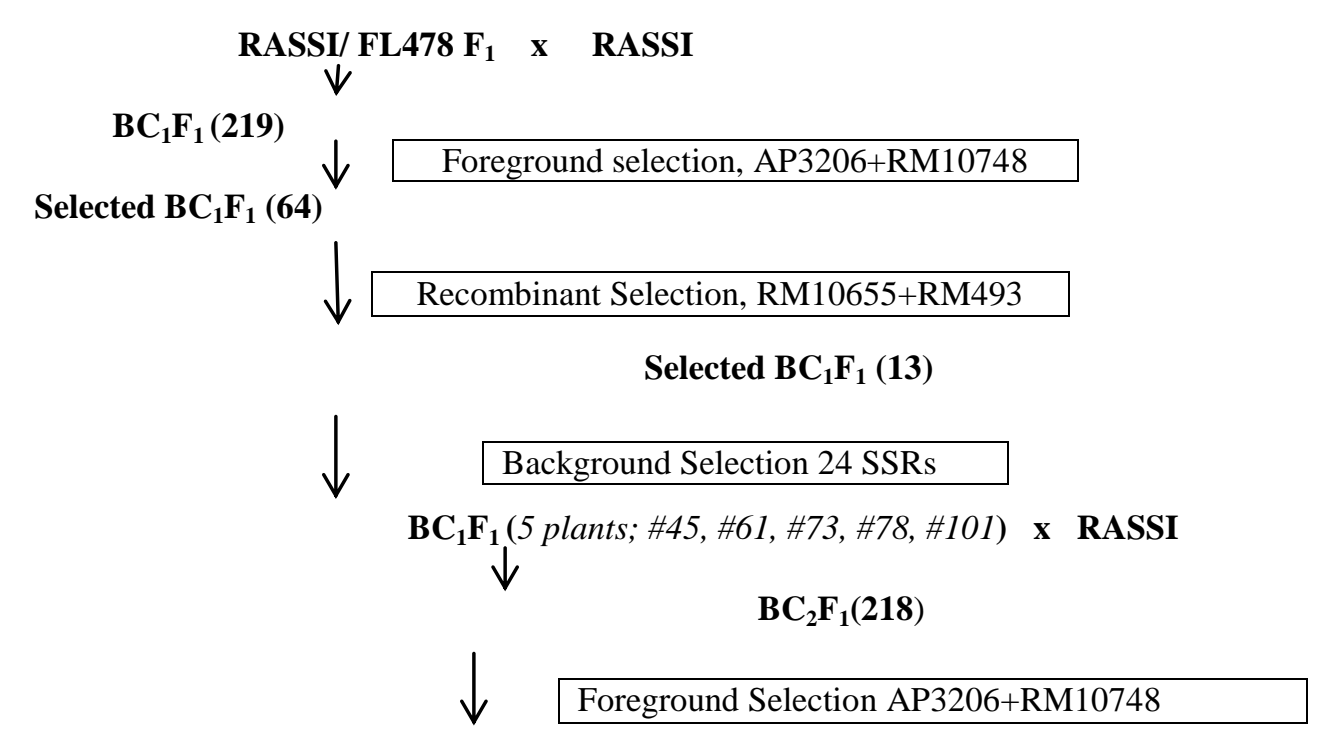

Selected $\mathrm{BC}_{2} \mathrm{~F}_{1}$ (194)
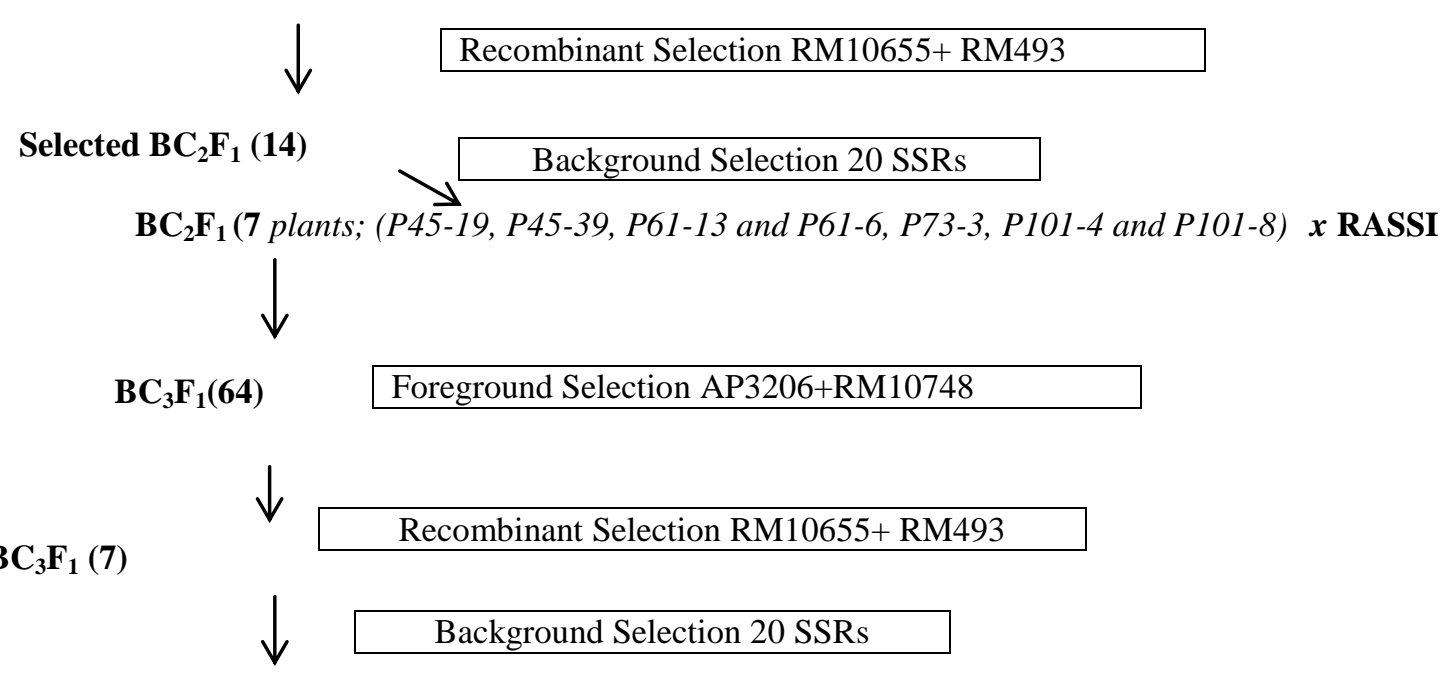

Selected $\mathbf{B C}_{\mathbf{3}} \mathbf{F}_{\mathbf{1}}$ (2) (\#45-39-1 and \#61-6-29)

$\downarrow \quad$ (x) Selfed

$\mathrm{BC}_{3} \mathrm{~F}_{2}(\mathbf{2 3 8 0})$
$\downarrow \quad$ Validation for Saltol $Q T L$ (fig.2)

$\downarrow$ 

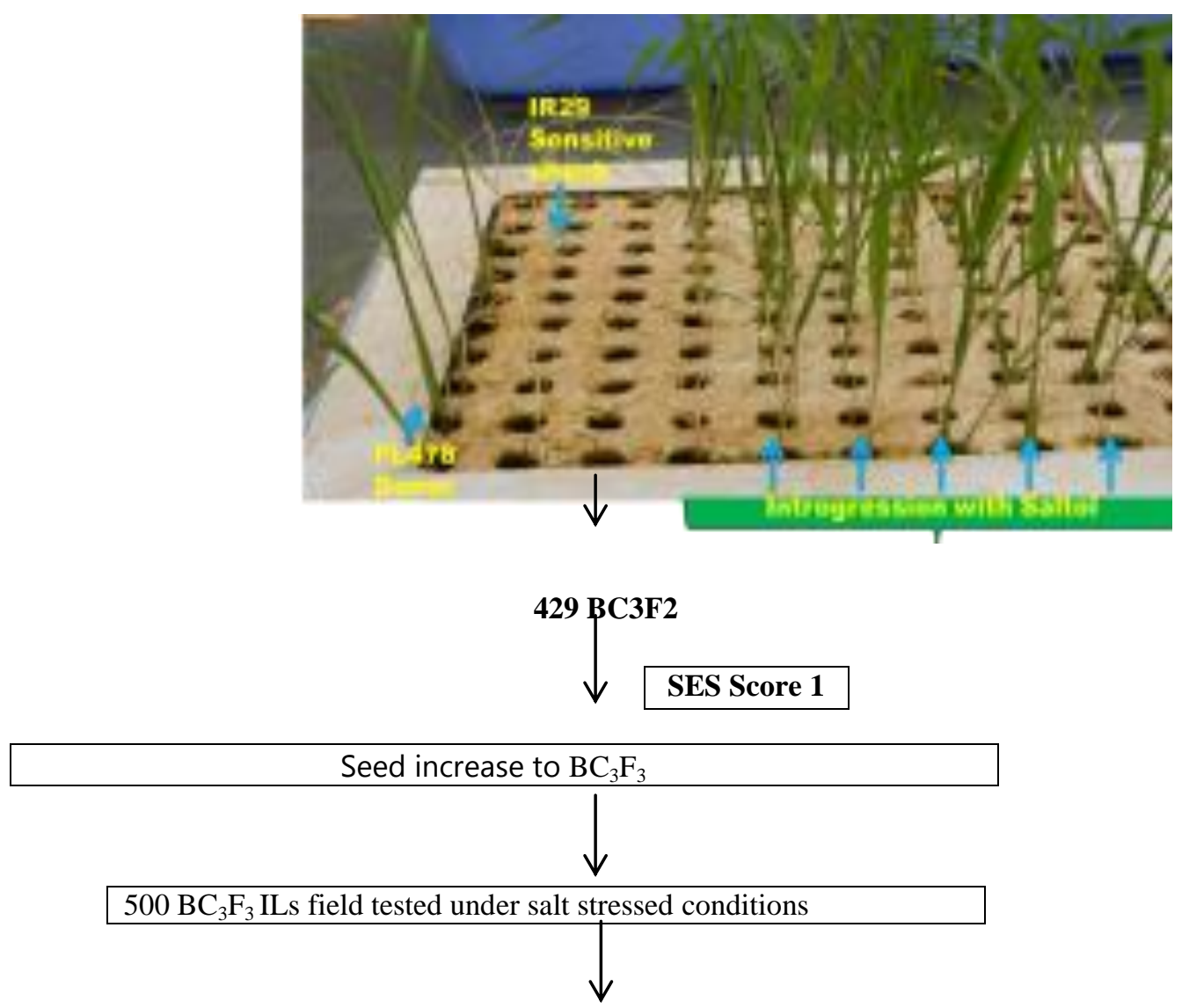

116 from $158 \mathrm{BC}_{3} \mathrm{~F}_{4}$ with SES score of 3.0 were agro morphologically characterized under non salt stress condition and also to produce sufficient seeds for subsequent field evaluation

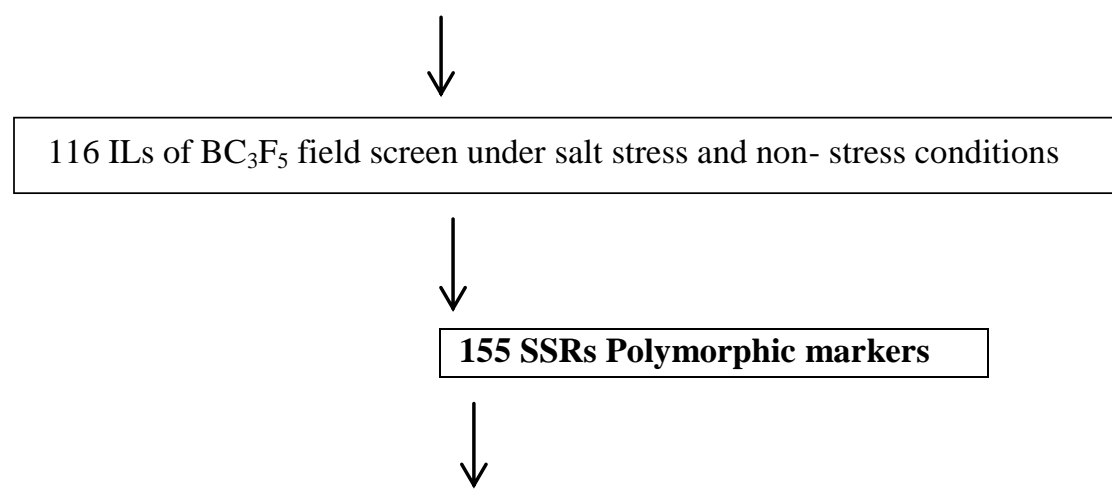

$80 \mathrm{ILs}$ of $\mathrm{BC}_{3} \mathrm{~F}_{6}$ field tested under stress and non- stress conditions 


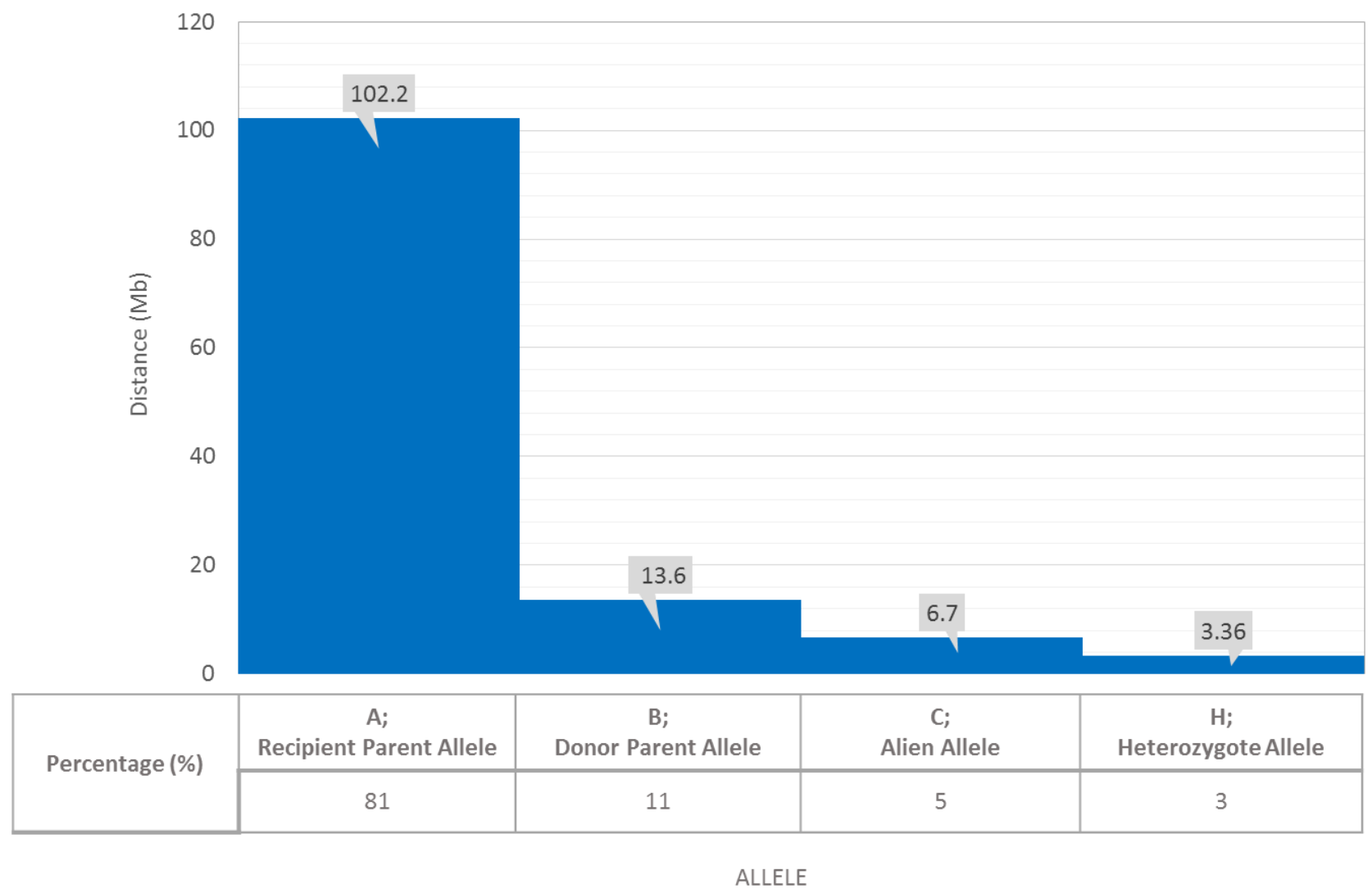

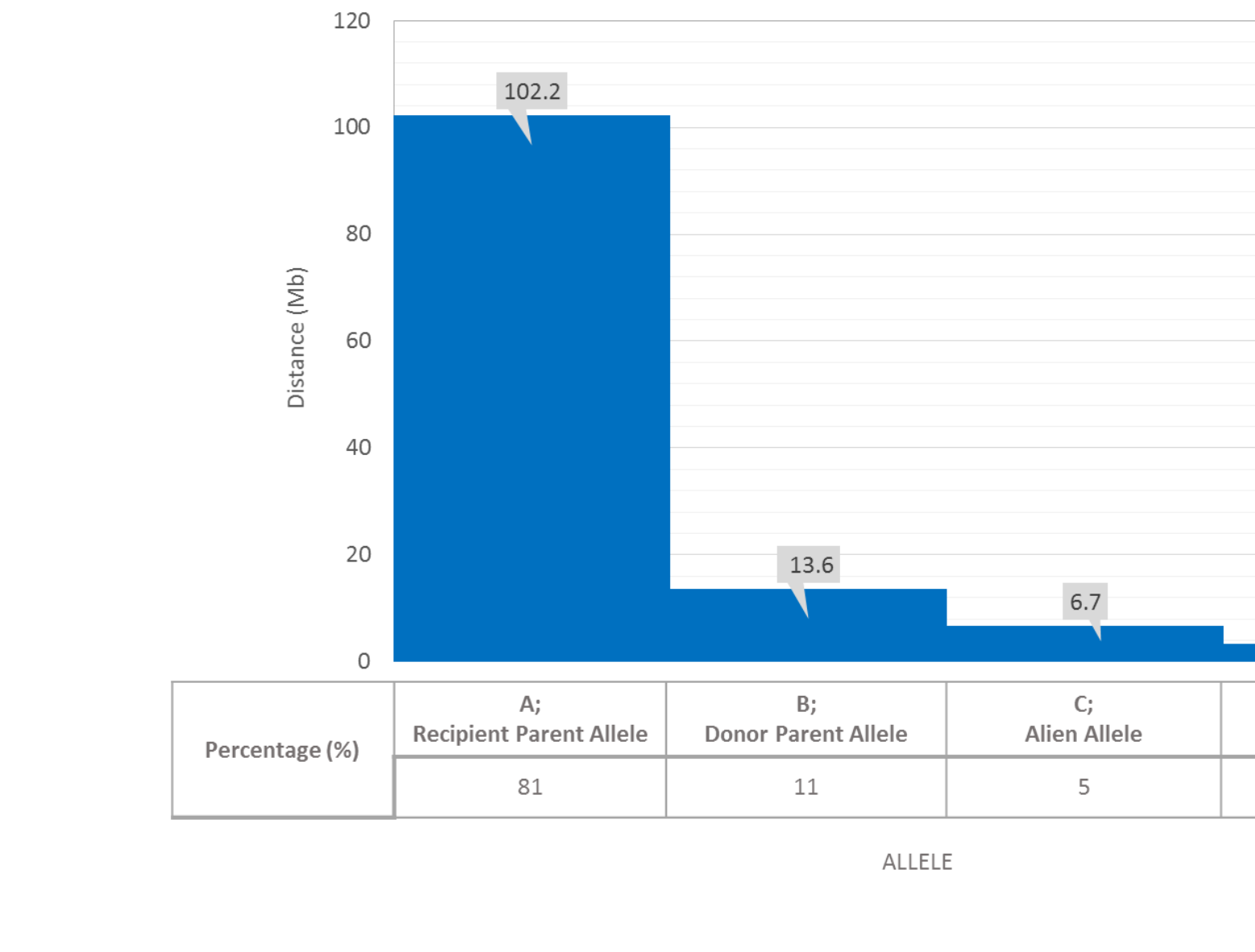

Figure 3. Percent allele's introgressed from each parent in the Introgression lines

.

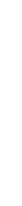
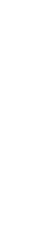

(1)

(1)








Figure 4a. Salt injury score (SES) for BC3F2 introgression lines for Saltol, recurrent parent (Rassi), susceptible check ( IR29) and donor parent/tolerant check ( FL478) at an EC of $12 \mathrm{dsm}^{-1}$

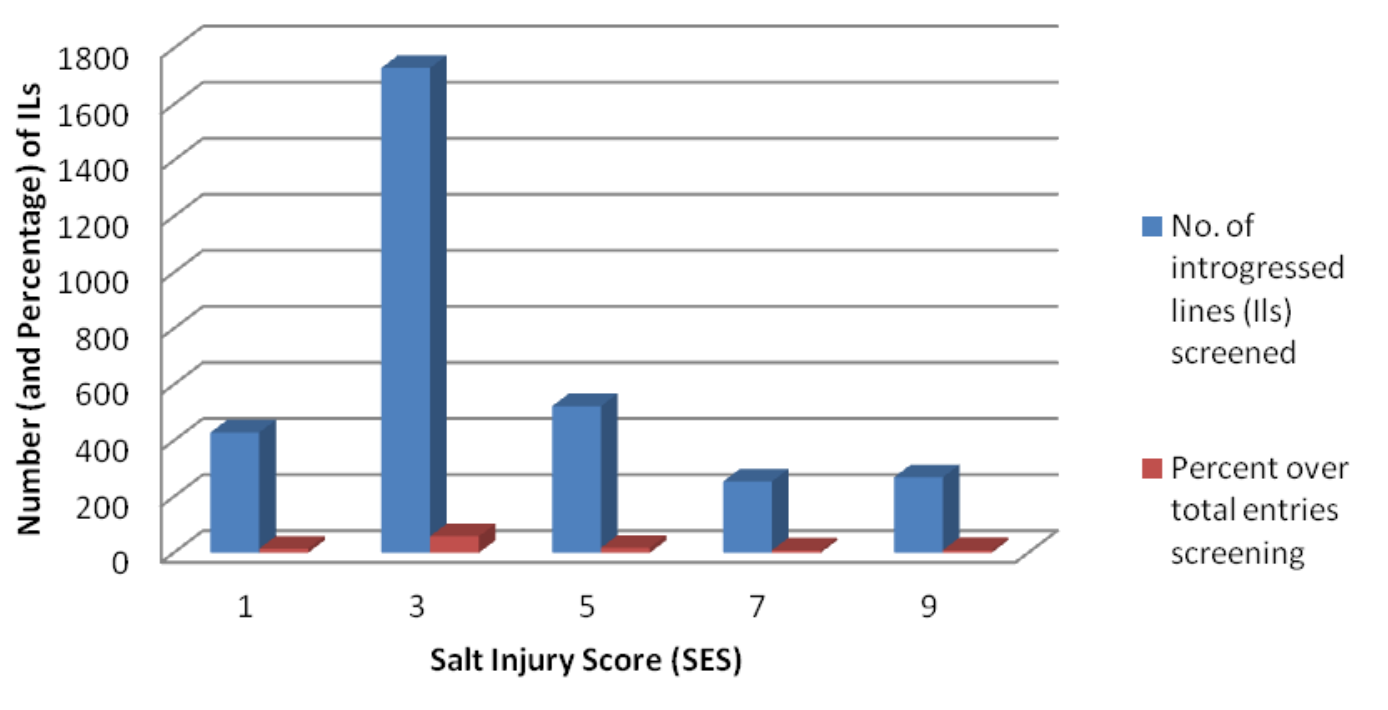

Figure 4b. Number of Saltol introgression lines survived at an EC of 12 dsm-2 under hydroponic conditions 


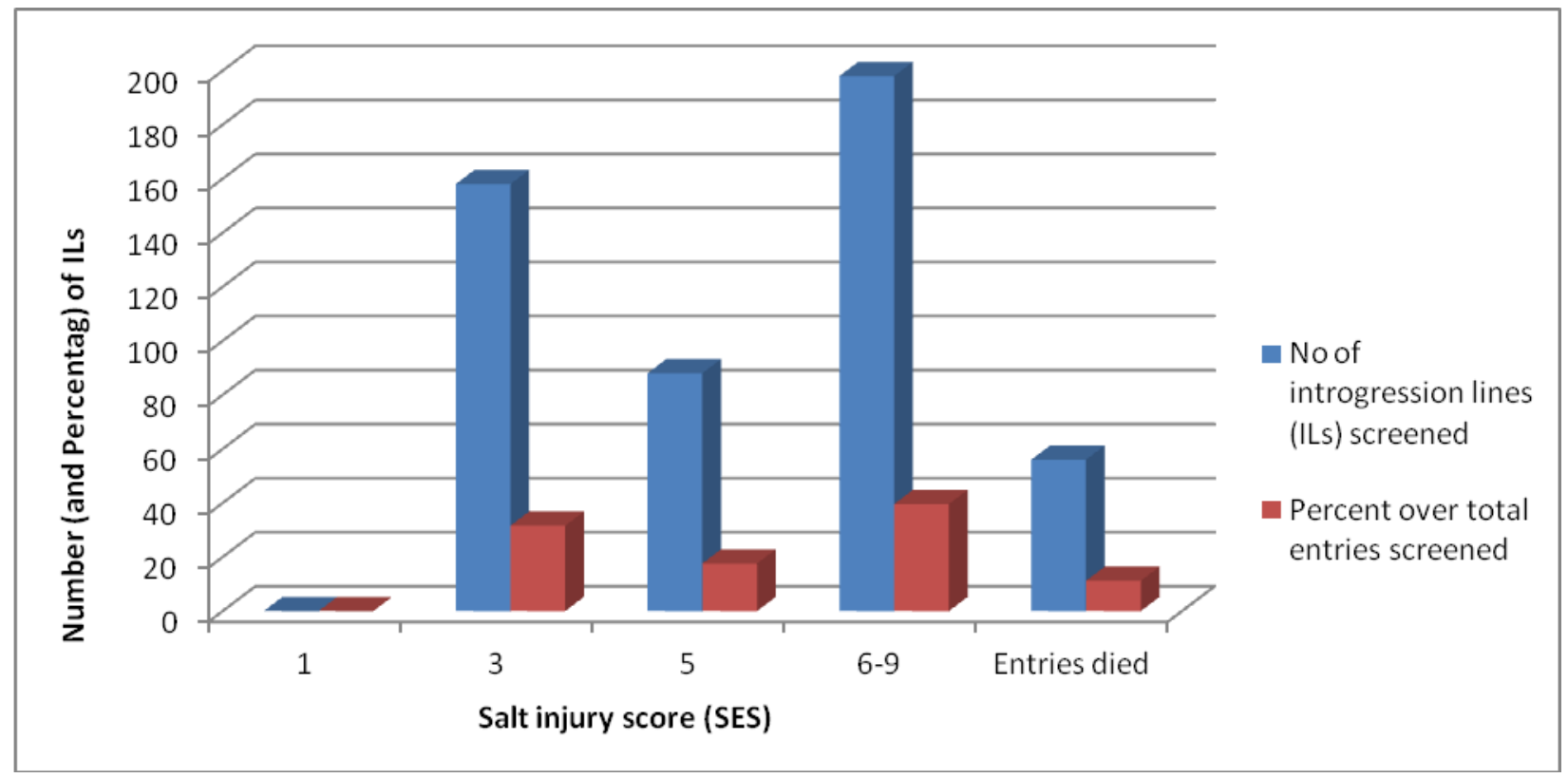

Figure 5. Salinity levels measured under the saline stress conditions during the 2011-2012 DS for BC3F3 Saltol introgression Lines 


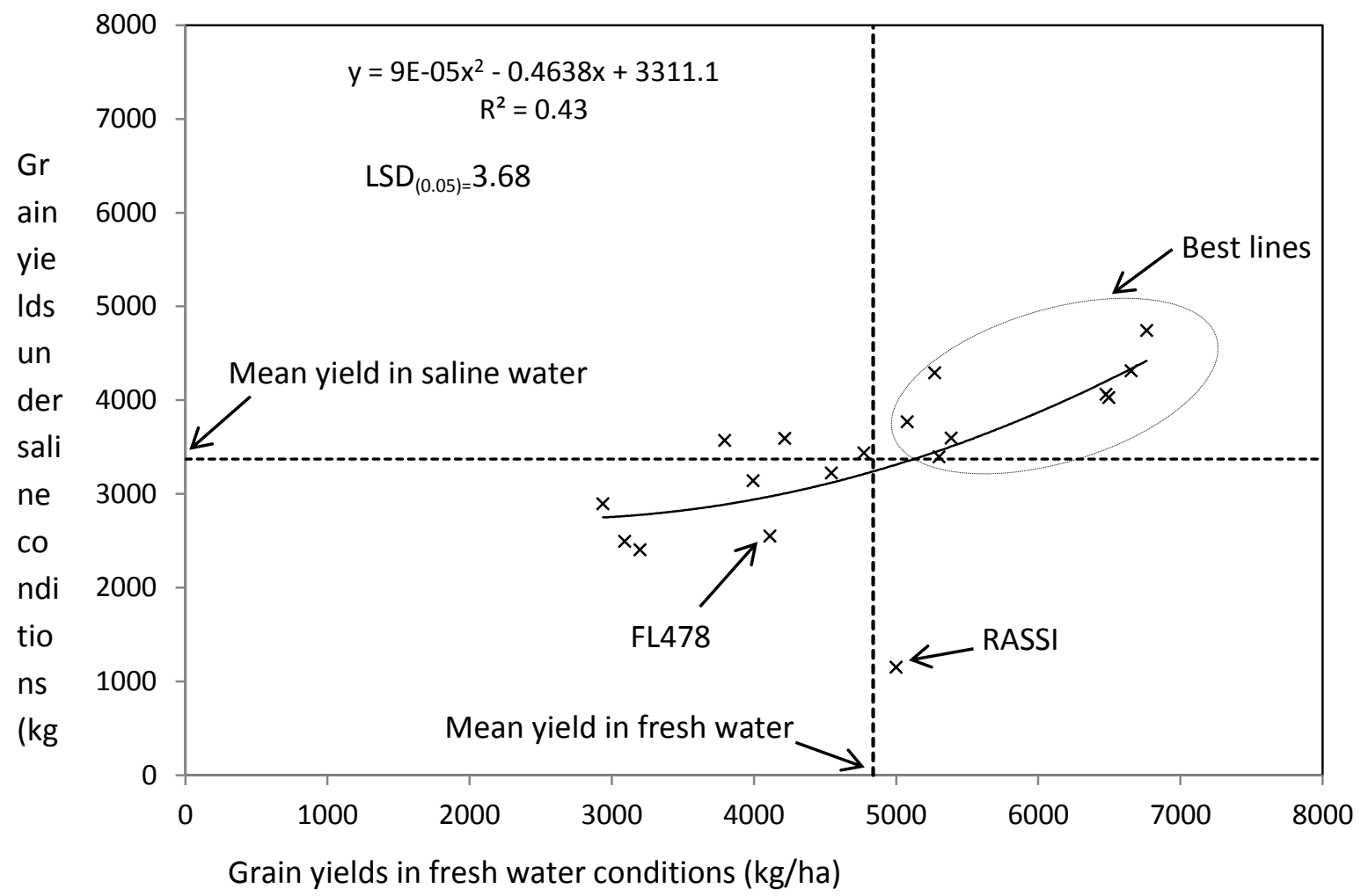

Figure 6: Regression of tolerant Saltol introgression lines under stress and non-stress conditions 


\section{Captions for Figures}

Figure 1. Development of salt tolerant Rassi-Saltol with details of markers used for foreground, recombinant, and background selection. The numbers of plants selected in each generation are indicated in parentheses

Figure 2. Validation/Screening for Saltol introgression lines for salt stress at early seedling stage $\left(E C=12 \mathrm{dsm}^{-1}\right)$

Figure3: Percent allele's introgressed from each parent in the Introgression lines

Figure4a. Salt injury score (SES) for BC3F2 introgression lines for Saltol, recurrent parent (Rassi), susceptible check (IR29) and donor parent/tolerant check (FL478) at an EC of $\left.12 \mathrm{dsm}-{ }^{1}\right)$

Figure 4b. Number of Saltol introgression lines survived at an EC of $12 \mathrm{dsm}-{ }^{1}$ under hydroponic conditions

Figure 5. Salinity levels measured under the saline stress conditions during the 20112012 DS for BC3F3 Saltol introgression Lines

Figure 6: Regression of tolerant Saltol introgression lines under stress and non-stress conditions 